\title{
Controlling Stroop effects by manipulating expectations for color words
}

\author{
JOSEPH TZELGOV, AVISHAI HENIK, and JACQUELINE BERGER \\ Ben Gurion University of the Negev, Beer Sheva, Israel
}

\begin{abstract}
An important characteristic of automatic processing is its uncontrollability. The Stroop phenomenon is regarded as a prototypical example of this characteristic of automatic processing, hence, the Stroop effect should not change when the percentages of color words versus neutral stimuli are manipulated to induce controlled processing. We found that Stroop interference decreased as the percentage of color words increased. Furthermore, the magnitude of the inhibitory component of the Stroop effect was negatively correlated with the percentage of color words; the facilitatory component was insensitive to the manipulation. These results suggest that the Stroop effect is controllable (see Logan, 1980) and that the locus of control is postlexical. The results also suggest that facilitation and inhibition are produced by different mechanisms and challenge those models of the Stroop phenomenon (e.g., Cohen, Dunbar, \& McClelland, 1990; Phaf, Van der Heijden, \& Hudson, 1990) that assume that a single processing mechanism causes facilitation and inhibition and that control affects facilitation and inhibition alike (Logan, 1980).
\end{abstract}

\section{Control in Stroop Effect}

Several theorists have proposed two different modes of information processing: automatic and nonautomatic (Neumann, 1984; Posner \& Snyder, 1975; Shiffrin \& Schneider, 1977; see also Jonides, Naveh-Benjamin, \& Palmer, 1985). Automatic processes are fast and effortless, while nonautomatic processes are slow and effortful. In addition, automatic processes are autonomous (see Zbrodoff \& Logan, 1986); they may occur without intention, triggered by the presence of a relevant stimulus in the task environment, and they run on to completion ballistically. In this sense, automatic processing, being autonomous, is hard to control, although memory-based approaches to automaticity suggest various ways of controlling automatic processing (see Logan, 1989).

When subjects name the color of the ink in which a color word is printed (e.g., when presented with the word green written in red ink, they are required to answer red); they respond more slowly when the printed name is incongruent with the ink color (e.g., red written in green) than when the printed name is congruent (e.g., green written

This article is based on a master's thesis in psychology, prepared by the third author under the supervision of the other two, at the Department of Behavioral Sciences at Ben Gurion University of the Negev. The results discussed in the article were reported at the 4th Conference of the European Society of Cognitive Psychology, September 1990, Como Italy, and at the 31st Annual Meeting of the Psychonomic Society, New Orleans, November, 1990. We wish to thank the staff of the Cognitive Psychology Laboratory for their help. We feel obliged to Margaret Intons-Peterson, Gordon Logan, and to the reviewers of earlier versions of this manuscript for their comments. The article also benefited from the comments of Trammel Neill. Correspondence concerning this article should be sent to J. Tzelgov, Department of Behavioral Sciences, Ben Gurion University of the Negev, Beer Sheva, Israel 84105 (e-mail: TZELGOV@BGUVM). in green), or when it is a neutral, color-unrelated stimulus (e.g., " $x x x$ " written in green). This difference, typically called the Stroop effect, suggests that subjects access the meaning of the word automatically; they cannot ignore the word even when asked to do so. The Stroop phenomenon has been introduced as a prime example of automatic processing (Posner \& Snyder, 1975) or of autonomy (rather than automaticity; see Zbrodoff \& Logan, 1986). Because of the supposed ballisticity of automatic processing, showing that the Stroop effect is subject to control would further constrain the concept of automaticity (see also Kahneman \& Chajczyk, 1983; Kahneman \& Henik, 1981; MacKinnon, Geiselman, \& Woodward, 1985).

How can we induce control? It is frequently assumed that when a process is sensitive to manipulation of expectations, it may be considered to be, at least in part, controllable (Jonides, 1981; Neely, 1977; Tzelgov, Henik, \& Friedrich, 1987). Manipulations of expectation have often been used within the priming paradigms to reveal the controlled aspect of cognitive processing (e.g., de Groot, 1984; Greenberg, 1988; Neely, 1977; Posner, 1978). We suggest that sensitivity of the Stroop effect to expectations can be taken as an indication for controllability of the effect. Stroop (and Stroop-like) effects have, indeed, been found to be sensitive to expectations. Logan (1980; Logan \& Zbrodoff, 1979) showed that changing the proportion of congruent (vs. incongruent) trials can affect the magnitude of Stroop (and Stroop-like) effects; increasing the proportion of congruent trials reduced the reaction times (RTs) to such stimuli and increased the RTs to incongruent trials. Similar results have been reported by Cheesman and Merikle (1986) and by Eglin and Hunter (1990). This manipulation affects the validity of the word meaning as a predictor of its color. The validity of the prime has been shown by several investigators to 
affect the semantic priming effect (e.g., de Groot, 1984; Neely, 1977). Thus, Logan (1980) interprets his results as reflecting a priming process. La Heij, Van der Heijden, and Schreuder (1985) also stress the similarity between the priming and the Stroop paradigms. Priming processes, therefore, may be one component in controlling the Stroop effect.

Tzelgov, Henik, and Leiser (1990) employed a bilingual version of the Stroop task and manipulated (between blocks) the proportion of stimuli in a given language. The Stroop effect was smaller in the "expected language" condition, suggesting that reading the color word can be controlled. Yet this occurred only in the first language of the subjects. Stroop interference in their second, less proficient, language was unaffected by the proportion of stimuli in that language. The investigators concluded that Stroop interference is controllable and that proficiency is a precondition for such control. It seems that in the advanced stages of acquiring reading skill, one learns to apply control mechanisms to the reading processes that are manifested in reduced Stroop interference. Because expectations may affect the Stroop effect, it should be possible to show this in a monolingual situation. In the experiment described here, we tested this hypothesis by manipulating the percentages of color words versus neutral trials.

\section{Explanations of the Stroop Effect and the Locus of its Control}

If automatic processing is uncontrollable (Hasher \& Zacks, 1979; Posner \& Snyder, 1975), then expectations should have no effect on the magnitude of the Stroop effect. On the other hand, if expectations help to exert control, then their effect should be manifested in a reduction of the Stroop effect. Specifically, when subjects expect color words, and know that some of them may interfere with the task they are asked to do (i.e., with reporting the ink's color), they should try to reduce the magnitude of the Stroop effect. Manipulations of the proportion of congruent stimuli increase the cue validity of the irrelevant dimension and thereby "tends to invoke the tactic of splitting attention over the two dimensions" (MacLeod, 1991, p. 177). We manipulated the expectations for color words without affecting the relation between the congruent and incongruent stimuli. This manipulation of expectations, in contrast to manipulations of congruent versus incongruent stimuli, leaves the cue validity of the irrelevant dimension unchanged.

Postlexical explanations attribute the effect to "conceptual encoding" (Seymour, 1977) and to suppression of the irrelevant word information (Neill, 1977; Neill \& Westberry, 1987; Tipper, 1985) or to interference at a stage of response decision (e.g., Dunbar \& MacLeod, 1984; Morton \& Chambers, 1973; Warren, 1972). Postlexical explanations of the Stroop effect (e.g., Hock \& Egeth, 1970; see also Kahneman \& Henik, 1981; Kahneman \& Treisman, 1984) attribute the effect to the perceptual encoding stage.
In a similar manner, it may be argued that control exerts its influence and reduces the Stroop effect either preor postlexically. The word may be inhibited from being processed before it accesses the semantic lexicon or it may act by reducing access to the lexicon. In these cases, control is prelexical. If lexical access does occur, the resulting conceptual or articulatory representation might be inhibited from influencing a decision about ink color. In this case, the locus of control is postlexical.

There are indications (e.g., Greenberg, 1988; Neely, Keefe, \& Ross, 1987; Tzelgov, Henik, \& Friedrich, 1987), at least in the priming paradigm, that cognitive processing is sensitive to the presence of various types of stimuli. Snow and Neely (1987) and Friedrich, Henik, and Tzelgov (1991) have shown that the tendency to access the conceptual level of representation may be increased by manipulating the proportion of related versus identical prime-target pairs. If control due to proportion manipulation acts by affecting the ease of lexical access, then the Stroop effect should be sensitive to the proportion of nonword neutrals and should be unaffected by changes in the proportion of word neutrals. To evaluate this possibility, we employed two kinds of neutral stimuli: For half of the subjects, noncolor words were employed as neutrals, and for the other half, neutral stimuli were a series of the same letter.

The use of neutral trials in Stroop situations allows one to distinguish between two components of the effect: inhibition and facilitation. The inhibition component is operationally defined as the difference in reaction time between responses to incongruent stimuli and neutral stimuli. The facilitation component is defined as the difference in reaction time between responses to neutral stimuli and congruent stimuli. If control operates prelexically, or if it is executed by reducing lexical access, then it would be consistent with the idea of "anticipatory" control (Neill, $1990 ;{ }^{1}$ Neill \& Lissner, 1988). The reading of the word would be inhibited before the word was identified and thus control would be insensitive to word meaning and affect facilitation and inhibition alike. Postlexical control may be anticipatory by the virtue of affecting congruent and incongruent stimuli alike (see Logan, 1980). ${ }^{2}$ Yet lexical access is a prerequisite for "reactive" control that results in differential effects on facilitation and inhibition. Therefore, we refer to the "reactivity" of the control process as an indication of its postlexical locus. According to the notion of "reactive control," the meaning of the word is suppressed only if it creates interference. This results in reducing inhibition and should not affect or increase facilitation.

\section{METHOD}

\footnotetext{
Subjects

Ninety-six students of Ben-Gurion University of the Negev, who were native speakers of Hebrew, participated in the experiment. All had normal or corrected-to-normal eyesight. No subject was color blind. Participation in the experiment was in partial fulfillment of course requirements.
} 


\section{Stimuli and Apparatus}

Four colors were employed in the experiment: red, green, blue, and yellow. The names of these colors in Hebrew consist of fourletter words. The incongruent stimuli were created by printing each of the four color names in the three other color inks on the computer screen. The congruent stimuli were created by printing each of the four color names in its own color. A pattern made of the Hebrew letter w ("shin") written four times (i.e., "wwuw") served as a nonword neutral stimulus. Four names of animals (lion, cat, rabbit, and mouse) were included as neutral (noncolor word) stimuli. All of these are also four-letter words in Hebrew and none of them contains the letter shin. Each neutral stimulus appeared an equal number of times in each color of ink.

The experiment was run individually on an Olivetti M240 microcomputer. The stimuli were presented on an EGA 12-in. color/ graphics monitor. A Gerbrand voice-operated relay (Model G1341T) interfaced to the microcomputer was employed to record subjects' vocal latencies.

\section{Design and Procedure}

There were eight groups of 12 subjects. For four groups, the animal names served as neutrals, and for the other four groups, the series of shin were employed as neutrals. The groups in each quadruple differed in the percentage of color words presented to them. In a given quadruple, for one group of subjects, the stimuli consisted of 96 congruent and 96 incongruent color words, so that half the trials were congruent and half were incongruent. For a second group, the stimulus set consisted of 72 congruent, 72 incongruent, and 48 color-unrelated stimuli. In a third group, the stimulus set consisted of 48 congruent, 48 incongruent, and 96 color-unrelated stimuli. In the stimulus set presented to a fourth group, there were 24 congruent, 24 incongruent and 144 color-unrelated stimuli. Thus, each subject in each condition participated in one experimental session of 192 trials.

The experiment began with a practice block of 48 trials. The proportion of the various types of stimuli in the practice block was identical to the proportion of the various stimulus types in the experimental blocks. The subjects sat opposite the display screen. The stimuli were presented in the center of the display screen, which was approximately $80 \mathrm{~cm}$ from the subjects' eyes. Each trial began with a fixation point (a plus sign) presented in the center of the screen for $300 \mathrm{msec}$. This was followed by a blank interval of $500 \mathrm{msec}$. The stimuli appeared at the end of the interval and remained in view until the subject's response into the microphone, which stopped the timer and removed the stimulus from the screen.
The computer measured reaction time in milliseconds from the onset of the stimulus to the onset of the subject's response. A keypress by the experimenter initiated the next trial. Errors were scored as the initial consonant sound (or more) that would indicate a color other than that of the current trial. The experimenter typed in the vocal response of the subject on one of four keys so that the computer could evaluate errors. Those trials on which technical errors occurred were presented again at the end of the session.

The subjects were tested individually. At the beginning of the experimental session, the task was explained to the subject, who was asked to ignore the written word and name the ink color as quickly as possible without making errors. Depending on the experimental group of the subject, each subject was told either that (1) all the words would be color words; (2) most of the words would be color words; (3) half of the words would be color words and half animal names (or series of shin); or (4) most of the words would be animal names (or series of shin).

Two independent variables were manipulated within subjects: type of neutral (animal names or series of shin) and degree of congruency (congruent, incongruent, or neutral). A third variable, percentage of color words (100\%, $75 \%, 50 \%$, or $25 \%$ ), was manipulated between subjects. The design was not factorial, however; there was no neutral condition when all the stimuli were color words. Reaction time was the main dependent variable in the experiment. Percentage of errors (PE) was also analyzed.

\section{RESULTS}

For each subject in each condition, a median RT of correct responses and the percentage of errors were calculated. Mean RTs and PEs as a function of the various experimental conditions are shown in Table 1. The far right column of Table 1 shows the Stroop effects in milliseconds for the various experimental conditions.

Because there are no neutrals when $100 \%$ of the stimuli are color words, the data could not be analyzed as a full factorial. Instead, two sets of analyses were performed. In the first set, the neutral condition was excluded from the analyses. These analyses focused on the Stroop effect (rather than on its components). The second set of analyses was performed on the data of the six groups whose stimuli did include neutral trials, and focused on the components of the Stroop effect.

Table 1

Mean Color-Naming RTs (in msec) and the Percent of Errors (PE) in Each Condition of the Experiment

\begin{tabular}{|c|c|c|c|c|c|c|c|}
\hline \multirow{3}{*}{$\begin{array}{l}\text { Color-word } \\
\text { Proportion }\end{array}$} & \multicolumn{6}{|c|}{ Congruency } & \multirow{3}{*}{$\begin{array}{l}\text { Stroop } \\
\text { Effect }\end{array}$} \\
\hline & \multicolumn{2}{|c|}{ Congruent } & \multicolumn{2}{|c|}{ Incongruent } & \multicolumn{2}{|c|}{ Neutral } & \\
\hline & RT & $\mathrm{PE}$ & RT & $\mathbf{P E}$ & RT & PE & \\
\hline \multicolumn{8}{|c|}{ Word Neutral } \\
\hline $\begin{array}{r}100 \% \\
75 \% \\
50 \% \\
25 \%\end{array}$ & $\begin{array}{l}616 \\
670 \\
617 \\
618\end{array}$ & $\begin{array}{l}1.7 \\
1.1 \\
1.4 \\
1.8\end{array}$ & $\begin{array}{l}731 \\
787 \\
760 \\
862\end{array}$ & $\begin{array}{r}2.9 \\
3.7 \\
3.3 \\
12.8\end{array}$ & $\begin{array}{l}733 \\
658 \\
692\end{array}$ & $\begin{array}{l}2.1 \\
1.0 \\
1.9\end{array}$ & $\begin{array}{l}115 \\
117 \\
143 \\
244\end{array}$ \\
\hline \multicolumn{8}{|c|}{ Nonword neutral } \\
\hline $\begin{array}{r}100 \% \\
75 \% \\
50 \% \\
25 \%\end{array}$ & $\begin{array}{l}632 \\
583 \\
607 \\
646\end{array}$ & $\begin{array}{l}1.4 \\
0.7 \\
1.7 \\
.34\end{array}$ & $\begin{array}{l}729 \\
700 \\
779 \\
842\end{array}$ & $\begin{array}{l}3.5 \\
3.1 \\
4.1 \\
5.2\end{array}$ & $\begin{array}{l}618 \\
623 \\
649\end{array}$ & $\begin{array}{l}0.5 \\
1.1 \\
1.7\end{array}$ & $\begin{array}{r}97 \\
117 \\
172 \\
196\end{array}$ \\
\hline
\end{tabular}

Note-The mean PE values appear in parentheses. 


\section{The Stroop Effect}

The exclusion of the neutral conditions resulted in a 2 (neutral type: animal name or shin) $\times 4$ (color-words percentage: $100 \%, 75 \%, 50 \%$, and $25 \%$ ) $\times 2$ (congruency: congruent and incongruent) factorial design. A three-way mixed-model analysis of variance revealed that responses to congruent stimuli were faster than responses to incongruent stimuli $\left[F(1,88)=515.15, M S_{\mathrm{e}}=2,102.84\right.$, $p<.00001]$, and that the RTs were increased as the proportion of color-word stimuli decreased $[F(3,88)=2.82$, $\left.M S_{e}=14,429.27, p<.05\right]$. The difference in RT between congruent and incongruent stimuli was moderated by percentage of color words $\left[F(3,88)=15.44, M S_{\mathrm{e}}=\right.$ $2,102.84, p<.00001]$. No additional significant effects were found.

Tests of simple main effects revealed that although the RTs for congruent stimuli were not affected by the percentage of color words $(F<1)$, RTs for the incongruent stimuli were very sensitive to this percentage $[F(1,88)=$ $\left.7.26, M S_{\mathrm{e}}=9,872.75, p<.0005\right]$. This sensitivity resulted in a linear increase in RTs for incongruent stimuli as a function of the reduction in the percentage of color words $[F(1,88)=18.65, p<.00005]$. Deviations from linearity, although significant $[F(2,88)=3.40, p<.05]$, explained less than $5 \%$ of the variability due to differences in the percentage of color words.

The basic error rate was low, averaging $3.6 \%$. The pattern of results for PE was similar, although less clear cut. There were fewer errors in the congruent than in the incongruent condition $\left[F(1,88)=49.60, M S_{\mathrm{e}}=12.36\right.$, $p<.000001]$, and when series of shin rather than words served as neutrals $\left[F(1,88)=7.64, M S_{\mathrm{e}}=11.13\right.$, $p<.0001]$. The percentage of color-related words significantly affected $\operatorname{PE}\left[F(3,88)=5.08, M S_{\mathrm{e}}=11.13\right.$, $p<.05]$. The percentage of color words interacted with neutral type $\left[F(3,88)=5.86, M S_{\mathrm{e}}=11.13, p<.001\right]$ and with congruency $\left[F(3,88)=8.52, M S_{\mathrm{e}}=11.13\right.$, $p<.00005$ ]. The triple interaction was also significant $\left[F(3,88)=2.74, M S_{e}=11.13, p<.05\right]$. Further analyses revealed that although in the case of word neutrals there was an interaction between congruency and colorwords percentages $\left[F(3,44)=7.11, M S_{e}=18.17\right.$, $p<.0005$ ], with nonword neutrals only the main effect of congruency was significant $\left[F(3,44)=31.78, M S_{\mathrm{e}}=\right.$ $6.54, p<.000001]$. The results appearing in Table 1 hint that even in these conditions the Stroop effect decreases as the percentage of color words increases. Given the relative insensitivity of error percentages, only the RT results are reported in subsequent analyses.

\section{Facilitation and Inhibition}

In order to focus on the components of the Stroop effect, the $100 \%$ color-word condition was excluded from the analysis, which resulted in a 2 (neutral type) $\times 3$ (color-words percentage: $75 \%, 50 \%$, and $25 \%$ ) $\times 3$ (congruent, neutral, and incongruent) factorial design. ${ }^{3} \mathrm{Re}-$ sponse times were longer in the word-neutral conditions (710) than in the nonword-neutral conditions (672) $\left[F(1,66)=4.24, M S_{e}=18,718.99, p<.05\right]$ and were longer for incongruent (788) than for neutral (662) and congruent stimuli $\left[F(2,132)=295.19, M S_{c}=1,813.82\right.$, $p<.000001]$. Neutral type interacted with congruency $\left[F(2,132)=5.05, M S_{\mathrm{e}}=1,813.82, p<.001\right]$. This interaction was caused by the difference in the RTs to the two types of neutrals: contrasting congruent and incongruent stimuli resulted in no interaction with neutral type $(F<1)$, indicating that neutral type affects congruent and incongruent stimuli similarly. The RTs to color words, as contrasted with neutrals, was affected by neutral type $\left[F(1,66)=12.94, M S_{\mathrm{e}}=90,721.84, p<\right.$ $.001]$. The RTs for both types of color stimuli were about equal in both conditions, but the response times to word neutrals $(694 \mathrm{msec})$ were longer than those to nonword neutrals $(662 \mathrm{msec})$. This pattern resulted in an increase in facilitation $\left[F(1,66)=13.82, M S_{\mathrm{e}}=77,231.41\right.$, $p<.001]$ and a decrease in inhibition $[F(1,66)=5.34$, $\left.M S_{\mathrm{e}}=133,202.60, p<.05\right]$ for word neutrals as compared with nonword neutrals. The interaction between neutral type and congruency did not reach significance $\left[F(2,66)=2.45, M S_{\mathrm{e}}=18,718.99\right.$, n.s. $]$. The most interesting result was the lack of a triple interaction $\left[F(4,132)=1.53, M S_{e}=1,813.82\right.$, n.s. $]$ and a significant interaction between color-words percentage and congruency $\left[F(4,132)=13.71, M S_{\mathrm{e}}=1,813.82\right.$, $p<.001]$. This latter result clearly indicates that the effect of the percentage of color words does not depend on whether the neutrals were words or nonwords.

In subsequent analyses, we tested the sensitivity of the facilitation and inhibition components to the percentage of color words. ${ }^{4}$ RTs to congruent stimuli $(623 \mathrm{msec})$ were faster than those to neutral stimuli $(662 \mathrm{msec})$, yielding significant evidence of facilitation $[F(1,66)=46.72$, $\left.M S_{e}=1,170.17, p<.00001\right]$. Facilitation was insensitive to percentage differences $\left[F(1,66)=1.10, M S_{e}=\right.$ $1,170.17$, n.s.]. By contrast, RTs to incongruent stimuli (788) reliably exceeded those to neutral stimuli by $126 \mathrm{msec}$, showing significant evidence of inhibition

\section{Facilitation and Inhibition}

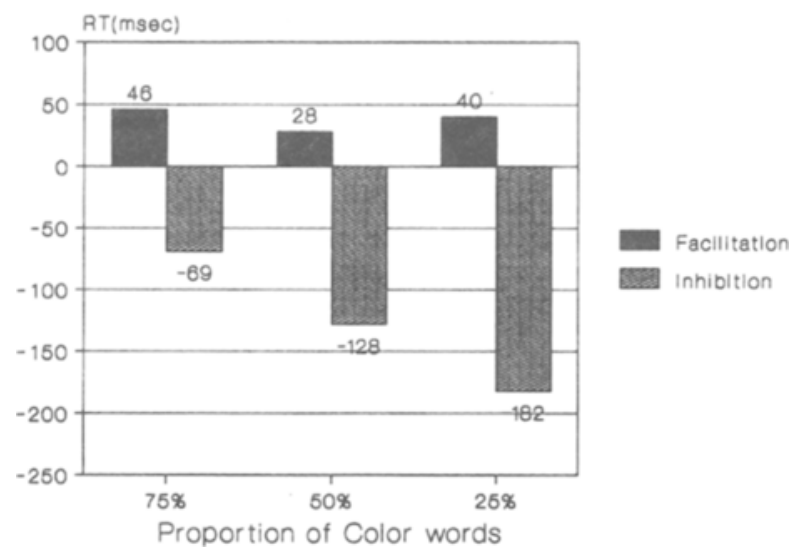

Figure 1. Facilitation and inhibition effects as a function of colorwords proportion. 
$\left[F(1,66)=283.25, M S_{\mathrm{e}}=2,018.22, p<.00001\right]$. In hibition increased with the decrease in percentage of color words, resulting in a significant interaction $[F(2,66)=$ 19.25, $M S_{\mathrm{e}}=2,018.22, p<.00001$ ] (see Figure 1).

A trend analysis of the interaction between inhibition and the percentage of color words revealed that inhibition decreases linearly with percentage $[F(1,66)=41.05$, $\left.M S_{\mathrm{c}}=2,018.22, p<.00001\right]$. The linear trend explained $99 \%$ of the sum of squares of the interaction while the facilitation component was insensitive to the percentage of neutral trials. ${ }^{5}$ Thus, the results of this analysis are clear: The magnitude of the inhibition components is linearly (and inversely) related to the percentage of color words.

To complete the picture, we note that the RTs for the neutral stimuli were not affected by changes in the percentage of color words $\left[F(2,66)=1.87, M S_{e}=\right.$ $4,585.97$, n.s.].

\section{DISCUSSION}

As expected, the Stroop effect was obtained in terms of both RTs and error percentages, in consonance with many experiments in the literature (for reviews, see Dunbar \& MacLeod, 1984; Dyer, 1973; MacLeod, 1991). Both its facilitatory and inhibitory effects were significant, with the facilitatory component being, although considerably smaller, consistent with the literature (see MacLeod, 1991). The subjects responded more slowly in the word-neutral conditions than in the nonword-neutral conditions. This difference in RTs was about equal to congruent and to incongruent stimuli but it was larger for neutrals (see also Klein, 1964; MacLeod \& Grant, 1991). Thus, the Stroop effect was about the same magnitude for both types of neutrals, but word neutrals resulted in increased facilitation and reduced inhibition. ${ }^{6}$ Thus, having word rather than nonword neutrals has both direct and indirect costs. Word neutrals may themselves be a source of interference (see also MacLeod, 1991), slowing processing in general. Paap and Ogden (1981) have shown that attention may be required, even for autonomous processing; Kahneman and Henik (1981) and Kahneman and Chajczyk (1983) have shown this to be true for the Stroop effect. Therefore, the indirect cost of including word neutrals in the experiment may reflect the strategy of distributing resources across the semantic network (in order to "read" the neutrals) rather than focusing it in the color area.

The Stroop effect was affected by expectations for color words as created by manipulations in the percentage of such words. Specifically, a decrease in the percentage of color words increased RTs for incongruent stimuli, but had no effect on RTs for congruent stimuli and neutrals. These effects resulted in an inhibition component that was negatively correlated with the proportion of color words and a facilitation component that was constant across conditions. Similar to the results reported by La Heij et al.
(1985) and Tzelgov et al. (1990) and to the proposition of Neill and Westberry (1987), our data imply that different processing may be involved in facilitation and inhibition, contradicting the dominant models of the Stroop effect that attribute facilitation and inhibition to a single processing mechanism (Coren, Dunbar, \& McClelland, 1990; Logan, 1980; Phaf, Van der Heijden, \& Hudson, 1990).

\section{Effects of Practice and Habituation}

We attribute this pattern of results to control exerted by the subject. Before stating such a conclusion, however, alternative explanations should be considered. The increase in the percentage of color words was achieved by increasing their number and, in parallel, by decreasing the number of the neutral trials. For example, in the condition of the $75 \%$ color words, there were 144 color words and 48 neutrals, whereas in the $25 \%$ color-words condition there were 144 neutrals and only 48 color words. This design was selected to create four groups with equal experience in the experimental task. Still, it may be argued that, although all the subjects had equal experience with the task, the experimental groups differed in relation to the opportunity to practice processing of the various types of stimuli. Logan's (1988) instance-based theory of automaticity predicts that increasing a proportion of given types of trials should speed up their processing due to instance accumulation (see Logan \& Klapp, 1991). We found that both neutral and congruent trials were insensitive to changes in their frequency, but that the RTs for incongruent trials were accelerated when the proportion of such stimuli was increased. The reduction in the RTs for incongruent stimuli is consistent with Logan's (1988) theory, but his theory would also predict a similar reduction in the RTs of congruent stimuli. Another possible interpretation is that, as the percentage of the color words increased, the subjects had more opportunity to practice control over the irrelevant dimension of color stimuli. This would be consistent with the argument made by Reisberg, Baron, and Kemler (1980). This "control due to practice" explanation predicts a reduction in the Stroop effect with the increase in number of color-word trials. That would still mean that people can acquire some control over the Stroop task; but, if that is the case, control is acquired simply by practice with a task that requires it. To put it differently, this view means that, with extended practice, subjects learn to suppress Stroop interference, and not necessarily that they control the effect via expectations. Such an interpretation makes sense because Reisberg et al. (1980) have shown that Stroop-like phenomena are reduced by practice.

Along the same lines, it may be argued that the decrease of the Stroop interference with the increase in the percentage of color words reflects increased habituation: When the same color stimuli are repeatedly presented, the response is facilitated due to the habituation of the orienting response toward the word meaning (see, e.g., 
Table 2

Mean Color-Naming RTs (in msec) in Each Condition and the Stroop Effect Across Neutral Types in the First 24 Color-Words Trials for Each Condition

\begin{tabular}{cccc} 
& \multicolumn{2}{c}{ Congruency } & \\
\cline { 2 - 4 } Proportion & Congruent & Incongruent & Stroop Effect \\
\hline $100 \%$ & 617 & 728 & 111 \\
$75 \%$ & 618 & 742 & 124 \\
$50 \%$ & 589 & 767 & 178 \\
$25 \%$ & 631 & 852 & 221 \\
\hline
\end{tabular}

Lowe, 1979; Tipper, Bourque, Anderson, \& Brehaut, 1989; Tipper \& Cranston, 1985; see also Reisberg et al., 1980 , for a similar interpretation).

To test these possibilities, we analyzed the data from the first 24 congruent and the first 24 incongruent trials of the subjects in all experimental groups. That means that for the $25 \%$ color-words group, we employed the data from all color-words trials, and for the $100 \%$ color-words group, we employed only the data of the first quarter of the congruent and the first quarter of the incongruent trials. This resulted in a 2 (type of neutral) $\times 4$ (percentage of color words) $\times 2$ (congruency) factorial design.

Because for the trials included in the analysis, the subjects in all groups did not differ in their experience with color words, both control due to practice and habituation hypotheses predicted an equal Stroop effect in all groups. By contrast, our original "control due to expectations", hypothesis predicted that the results of this analysis would not differ from the results of the original analyses, that is, the Stroop effect would decrease with the increase in percentage of color words.

The analysis was based on the data of 94 subjects. ${ }^{7}$ RTs increased with the decrease in the proportion of color words $\left[F(3,86)=3.83, M S_{\mathrm{e}}=13018.04, p<.05\right]$, and the responses to congruent trials were faster than those to incongruent trials $\left[F(1,86)=505.66, M S_{e}=2321.84\right.$, $p<.001]$. The interaction between neutral type and percentage of color words was also significant $[F(3,86)=$ 2.84, $\left.M S_{\mathrm{e}}=13018.04, p<.05\right]$. The most important finding of this analysis was the proportion of color words $\times$ congruency interaction $\left[F(3,86)=13.33, M S_{\mathrm{e}}=\right.$ 2321.84, $p<.001$ ]. No additional significant effects were found. The mean RTs (across neutral types) as a function of the proportion of color words and congruency appear in Table 2 .

The significant interaction occurred because the Stroop effect increases with the decrease in the percentage of color words. Thus, we reject the hypotheses of control due to practice and habituation, and accept the view that the differences in the magnitude of the Stroop effect were caused by differential expectations.

\section{The Locus of Stroop Control by \\ Expectations of Color Words}

Our results are consistent with studies that found that manipulation of expectations can affect Stroop interference (Cheesman \& Merikle, 1986; Eglin \& Hunter, 1990;
Logan, 1980; Logan \& Zbrodoff, 1979; but see Logan, Zbrodoff, \& Williamson, 1984). Logan (1980) proposed a model that explains the effect of the proportion of congruent stimuli in Stroop (and Stroop-like) tasks. The model is based on the idea that the processing of color is primed by processing of the meaning of the word. According to the model, the patterns of facilitation and inhibition in the Stroop paradigm can be explained by a single mechanism that combines evidence from different sources and selects a response based on the combined information. The effects of attention and automaticity are expressed as weights on each of the dimensions of the stimulus situation that reflect the rate at which evidence is gained. Automatic weights are assumed to be constant in sign (facilitatory or inhibitory) and magnitude over situations, purposes, and intentions, reflecting their relative permanence. Attentional weights are assumed to vary in sign, reflecting their strategic flexibility and, in particular, to increase in accordance with prime validity to optimize performance (Logan \& Zbrodoff, 1979).

Neely (1991) and Neely and Keefe (1989) distinguish among three processes in (semantic) priming. Logan's (1980) model may be said to be similar to "expectancybased priming" (Neely, 1991) and, in particular, to the expectancy mechanisms proposed by Posner and Snyder (1975). However, the concept of control, as reflected in our present study, is different from that suggested by Posner and Snyder (see also Neely, 1977). Specifically, their proposals concentrate on manipulations that operate by changing the distribution of processing resources within the semantic network. In line with that, the benefit of an increase in facilitation has the cost of increased inhibition. Logan's model predicts that facilitation and inhibition will be similarly affected by similar manipulations. Our finding that proportion of color words versus neutrals affected inhibition but not facilitation is inconsistent with this prediction. Thus, we conclude that, given the present results, there is no basis to assume that the same processing mechanism is involved in the modulation of the Stroop effect by the proportion of congruent (versus incongruent) stimuli and the proportion of color words versus neutrals.

Tzelgov et al. (1990) employed a bilingual version of the Stroop task and found that expectations for stimuli in a given language decrease the Stroop effect. This result was limited to expectations for stimuli in the subjects' first language. Although no neutrals were employed in these experiments, only the incongruent trials were affected by expectations. This implies that language expectations modify the inhibition component in a way that is similar to that of expectations for color words. The results of various experiments indicate that surface-different stimuli access the semantic representation level through different routes and that concepts are represented in an amodal representation (see Chen \& Leung, 1989; de Groot \& Nas, 1991; Kroll \& Curley, 1988; Potter, So, von Eckhart, \& Feldman, 1984; Snodgrass, 1984; Tzelgov \& Henik, 1990b). In the experiments of Tzelgov et al. (1990), if control was operating by limiting access to the semantic representation level rather than by affecting processing 
within the semantic network, then there should be no difference in its effects on congruent and incongruent trials in any language. Thus, it may be (although such a conclusion may be premature) that stimulus language expectations and expectations for color words control the Stroop effect through the same basic process. This process, however, seems to be different from the priming mechanism that explains the effect of proportion of congruent stimuli on Stroop interference (Logan, 1980).

\section{Conceptions of Stroop Control}

We interpret the reduction of the Stroop effect by expectation as reflecting a control process. Although nonword neutrals were processed faster than word neutrals, the effect of percentage of color words on Stroop interference did not depend on whether the neutrals were words or nonwords. Therefore, it may be argued that control over the interference is not exerted by reducing lexical access. Furthermore, only the magnitude of the inhibitory component is affected by the percentage of color words. This implies that the effect of percentage is "reactive," that is, the information about lexicality is utilized by the control mechanism. This is consistent with postlexical explanations of Stroop control.

Tzelgov et al. (1990) attributed the Stroop effect to the "conceptual encoding" stage (see Seymour, 1977) at the semantic level, and interpreted control as reflecting suppression of irrelevant activation. It is possible that proficiency of a language is a precondition for such a suppression process (see Tipper et al., 1989; Tzelgov et al., 1990). Our current subjects (as subjects in most monolingual Stroop experiments) were proficient in the language employed in the experiment and, given the similarity of the effects of the percentage of trials in a given language and the percentage of color words, we suggest that the two manipulations affect the same stage.

Seymour's (1977) model attributes the Stroop effect to the simultaneous activation of two nodes in the semantic network. The extra processing time reflects the processes involved in the suppression of irrelevant activation. Studies using negative priming techniques also support the view that selection of relevant information may proceed by the active suppression of irrelevant information (Neill \& Westberry, 1987; Tipper, 1985; Tipper \& Cranston, 1985; Yee, 1990). We suggest that this suppression process is sensitive to the percentage of color words. The effect of color-words percentage is reactive; the meaning of the word is accessed before being suppressed. Along the same lines, Driver and Tipper (1989) proposed that the unattended prime stimulus in their negative priming experiments is identified or categorized before being suppressed (see also Tipper, 1985; Tipper \& Cranston, 1985). Evidence that the Stroop conflict occurs earlier than the response-execution stage (i.e., at a semantic level) has also been presented by Glaser and Glaser (1982).

Neill (1977) found that when two successive Stroop items were related so that the ink color of the second item matched the distracting word of the first, subjects took longer to name the color than when the successive stim- uli were unrelated. This indicates that subjects execute an active suppression process in the temporally leading trial. It may be that this process is affected by changes in the percentage of color words. Neill and Westberry (1987) suggested a modified version of Tipper's (1985; see also Tipper \& Cranston, 1985) selective inhibition model. According to this model, facilitation and inhibition reflect different processing stages and, in particular, what is inhibited is the access to overt response. Applying this model to the modulation of the Stroop effect by colorwords percentage would mean that in this stage, control works by preventing the results of automatic processes from affecting overt behavior. This does not rule out the possibility that at a different processing stage another control mechanism that mainly affects facilitation, or both facilitation and inhibition, is active (see Tzelgov \& Henik, 1990a). The difference among the effects of the various kinds of expectations (see our discussion above) could possibly indicate either that control operates at more than one stage of processing, switching to a certain level, depending on the task and the manipulation of expectations, or that qualitatively different types of control are operating. There is some indication of the ability to exert control at different levels of processing (e.g., Keele \& Neill, 1978).

The presence of Stroop interference demonstrates that one cannot avoid processing the word, and that its identity affects the response to the relevant aspect of the target stimulus, that is, the color. In this sense, automatic processing is indeed involuntary. However, evidence of a reduction in the Stroop interference when interference is expected suggests that either the processing of the word is being controlled or the results of its processing are subject to control. In either case, the conceptualization of the relations between control and automatic processing requires modification.

\section{REFERENCES}

Cheesman, J., \& Merikle, P. M. (1986). Distinguishing conscious from unconscious perceptual process. Canadian Journal of Psychology, 40, 343-367.

Chen, H-C., Leung, Y-S. (1989). Patterns of lexical processing in nonnative language. Joumal of Experimental Psychology, 15, 316-325.

Cohen, J. D., Dunbar, K., a McClelland, J. L. (1990). On the control of automatic processes: A parallel distributed processing model of the Stroop effect. Psychological Review, 97, 332-361.

De Groot, A. M. B. (1984). Primed lexical decisions: Combined effects of the proportion of related prime-target pairs and the stimulus onset asynchrony. Quarterly Joumal of Experimental Psychology, 36A, 253280

DE Groot, A. M. B., * NAS, G. (1991). The bilingual mental lexicon: Some within- and between-language connections between lexical representations. Journal of Memory \& Language, 30, 90-123.

Driver, J., \& Tipper, S. P. (1989). On the nonselectivity of "selective" seeing: Contrasts between interference and priming in selective attention. Joumal of Experimental Psychology: Human Perception \& Performance, 15, 304-314.

Dunbar, K., \& Macleod, C. M. (1984). A horse race of a different color: Stroop interference patterns with transformed words. Journal of Experimental Psychology: Human Perception \& Peformance, 10, 622-639.

DYER, F. N. (1973). The Stroop phenomenon and its use in the study of perceptual, cognitive, and response processes. Memory \& Cognition, 1, 106-120. 
Eglin, M., Hunter, A. (1990). Cuing efficiency in a Stroop-like task with visual half field presentation. Memory \& Cognition, 18, 459-468.

Frjedrich, F. J., Henik, A., \& Tzelgov, J. (1991). Automatic processing in lexical access and spread of activation. Journal of Experimental Psychology: Human Perception \& Performance, 17, 792-806.

Glaser, M. O., Glaser, W. R. (1982). Time course analysis of the Stroop phenomenon. Joumal of Experimental Psychology: Human Perception \& Performance, 8, 875-894.

GReEnBerg, S. (1988). Are letters codes always activated? (IPDM Report No. 57). Israel: Haifa University.

Hasher, L., \&ACKS, R. T. (1979). Automatic and effortful processes in memory. Joumal of Experimental Psychology: General, 108, 356-388.

Hock, H. S., EGETH, H. E. (1970). Verbal interference with encoding in a perceptual classification task. Joumal of Experimental Psychology, 83, 299-303.

JONIDES, J. (1981). Voluntary versus automatic control over the mind's eye's movement. In J. Long \& A. Baddeley (Eds.), Attention and performance $I X$ (pp. 187-204). Hillsdale, NJ: Erlbaum.

Jonides, J., Naveh-Benjamin, M., \& Palmer, J. (1985). Assessing automaticity. Acta Psychologica, 60, 157-171.

KAhNeman, D., ChasCZYK, D. (1983). Tests of the automaticity of reading: Dilution of Stroop effects by color-irrelevant stimuli. Journal of Experimental Psychology: Human Perception \& Performance, 9, 497-509.

Kahneman, D., Henik, A. (1981). Perceptual organization and attention. In M. Kubovy \& J. R. Pomerantz (Eds.), Perceptual organization (pp. 181-211). Hillsdale, NJ: Erlbaum.

Kahneman, D., Treisman, A. (1984). Changing views of automaticity. In R. Parasuraman \& D. R. Davies (Eds.), Varieties of anention (pp. 29-41). Orlando, FL: Academic Press.

KeELE, S. W., NeILL, W. T. (1978). Mechanisms of attention. In E. C. Carterette \& M. P. Friedman (Eds.), Handbook of perception (Vol. 9, pp. 3-47). New York, NY: Academic Press.

KLEIN, G. S. (1964). Semantic power measured through the inference of words with color naming. American Journal of Psychology, 77, 567-588.

Kroll, J. F., CurLeY, J. (1988). Lexical memory in novice bilinguals: The role of concepts in retrieving second language words. In M. Grunberg, P. Morris, \& R. Sykes (Eds.), Practical aspects of memory (Vol. 2, pp. 389-395). London: John Wiley \& Sons.

la HeiJ, W., Van der Heijden, A. H. C., Schreuder, R. (1985) Semantic priming and Stroop-like interference in word naming task. Journal of Experimental Psychology: Human Perception \& Performance, 11, 62-70.

LOGAN, G. D. (1980). Attention and automaticity in Stroop and priming tasks: Theory and data. Cognitive Psychology, 12, 523-553.

LOGAN, G. D. (1988). Towards an instance theory of automatization. Psychological Review, 85, 492-527.

LoGAN, G. D. (1989). Automaticity and cognitive control. In J. S. Neuman \& J. A. Bargh (Eds.), Unintended thought (pp. 52-74). New York, NY: Guilford.

LOGAN, G. D., KLAPP, S. T. (1991). Automatizing alphabet arithmetic: I. Is extended practice necessary to produce automaticity. Journal of Experimental Psychology: Learming. Memory, \& Cognition, 17, 177-193.

Logan, G. D., \& Zbrodoff, N. J. (1979). When it helps to be misled: Facilitative effects of increasing the frequency of conflicting stimuli in a Stroop-like task. Memory \& Cognition, 7, 166-174.

LogAN, G. D., Zbrodoff, N. J., \& Williamson, J. (1984). Strategies in the color-word Stroop task. Bulletin of the Psychonomic Society, 22, 135-138.

LowE, D. G. (1979). Strategies, context, and mechanisms of response inhibition. Memory \& Cognition, 13, 74-80.

Mackinnon, D. P., Geiselman, R. E., \& Woodward, J. A. (1985). The effects of effort on Stroop interference. Acta Psychologica, 58, 225-235.

MACLEOD, C. M. (1991). Half a century of the Stroop effect: An integrative review. Psychological Bulletin, 109, 163-203.
Macleod, C. M., \& Grant, S. A. (1991, November). The Stroop effect: Incorporating noncolor words into the response set. Paper presented at the 32nd Annual Meeting of the Psychonomic Society, San Francisco, CA.

Morton, J., Chambers, S. M. (1973). Selective attention to words and colors. Quarterly Joumal of Experimental Psychology, 25, 387-397.

NeELY, J. H. (1977). Semantic priming and retrieval from lexical memory: Roles of inhibition, less spreading activation, and limited-capacity attention. Joumal of Experimental Psychology: General, 106, 226-254.

NeELY, J. H. (1991). Semantic priming effects in visual word recognition: A selective review of current findings and theories. In D. Besner \& G. Humphreys (Eds.), Basic processes in reading: Visual word recognition (pp. 264-336). Hillsdale, NJ: Erlbaum.

NeELY, J. H., KeEF, D. E. (1989). Semantic context effects on visual word recognition: A hybrid prospective/retrospective processing theory. In G. H. Bower (Ed.), The Psychology of learning and motivation: Advances in research and theory (Vol. 24, pp. 207-248). New York, NY: Academic Press.

Neely, J. H., Keefe, D. E., \& Ross, K. L. (1987, November). Retrospective postlexical processes produce the proportion effects in semantic priming. Paper presented at the 28th Annual Meeting of the Psychonomic Society, Seattle, WA.

NEILL, W. T. (1977). Inhibitory and facilitatory processes in selective attention. Journal of Experimental Psychology: Human Perception \& Performance, 3, 444-450.

NeILL, W. T., LISSNER, L. S. (1988, April). Attention and selective inhibition in alphanumeric character matching. Paper presented at the Annual Meeting of the Eastem Psychological Association, Buffalo, NY.

NeILL, W. T., \& Westberry, R. L. (1987). Selective attention and the suppression of cognitive noise. Journal of Experimental Psychology: Learning, Memory, \& Cognition, 13, 327-334.

Neumann, O. (1984). Automatic processing: A review of recent findings and a plea for an old theory. In W. Prinz \& A. F. Sanders (Eds.), Cognition and automatic processing (pp. 255-293). Berlin: SpringerVerlag

PAAP, K. R., \& OGden, W. G. (1981). Letter encoding in an obligatory but capacity-demanding operation. Joumal of Experimental Psychology: Human Perception \& Performance, 7, 518-528.

Phaf, R. H., Van der heijden, A. H. C., Hudson, P. T. W (1990). Slam: A connectionist model for attention in visual selection task. Cognitive Psychology, 22, 273-341.

PosNer, M. I. (1978). Chronometric explorations of mind. Hillsdale, NJ: Erlbaum.

Posner, M. I., \&Nyder, C. R. R. (1975). Attention and cognitive control. In R. L. Solso (Ed.), Information processing and cognition: The Loyola symposium (pp. 55-85). Hillsdale, NJ: Erlbaum.

Potter, M. I., So, K-F., von Eckhart, B., Feldman, L. B. (1984). Lexical and conceptual representation in beginning and proficient bilinguals. Journal of Verbal Learning \& Verbal Behavior, 23, 23-84. Reisberg, D., BAron, J., Kemler, D. G. (1980). Overcoming Stroop interference: The effect of distractor potency. Joumal of Experimental Psychology: Human Perception \& Pefformance, 6, 140-150.

SEYmour, P. H. K. (1977). Conceptual encoding and locus of the Stroop effect. Quarterly Journal of Experimental Psychology, 29, 245-265.

Shiffrin, R. M., SChNeider, W. (1977). Controlled and automatic human information processing: $\mathbf{\Pi}$. Perceptual learning, automatic attending, and a general theory. Psychological Review, 84, 127-190. SNODGRAss, J. G. (1984). Concepts and their surface representations. Journal of Verbal Learning \& Verbal Behavior, 23, 3-22.

SNOw, N., NeELY, J. H. (1987, November). Reduction of semantic priming from inclusion of physically related prime-target pairs. Paper presented at the 28th Annual Meeting of the Psychonomic Society, Seattle, WA

TIPPER, S. P. (1985). The negative priming effect: Inhibitory effects of ignored primes. Quarterly Joumal of Experimental Psychology, 37A, $571-590$.

Tipper, S. P., Bourque, T. A., Anderson, S. H., Brehaut, J. C. (1989). Mechanisms of attention: A developmental study. Joumal of Experimental Child Psychology, 48, 353-378. 
Tipper, S. P., \& Cranston, M. (1985). Selective attention and priming: Inhibitory and facilitatory effects of ignored primes. Quarterly Journal of Experimental Psychology, 37A, 591-611.

Tzelgov, J., \& Henik, A. (1990a, November). Controlling Stroop effect. Paper presented at the 31st Annual Meeting of the Psychonomic Society, New Orleans, LA.

Tzelgov, J., \& Henik, A. (1990b). The insensitivity of semantic relatedness effect to surface differences and its implications. In P. J. D Drenth, J. P. Sergeant, \& R. J. Takens (Eds.), European perspectives in psychology (pp. 385-402). London: John Wiley \& Sons.

Tzelgov, J., Henik, A., \& Fredrich, F. (1987). Semantic activation during word and picture recognition (Final Report, Project 84-00050). Beer-Sheva: Israel-U.S. Binational Science Foundation.

Tzelgov, J., Henik, A., \& Leiser, D. (1990). Controlling the Stroop interference: Evidence from a bilingual task. Joumal of Experimental Psychology: Learning, Memory, \& Cognition, 16, 760-771.

WARREN, R. E. (1972). Stimulus encoding and memory. Joumal of Experimental Psychology, 94, 90-100.

YEE, P. L. (1990). Semantic inhibition of ignored words during a figure classification task. Quarterly Journal of Experimental Psychology, 43A, 127-153

ZBrodoff, J. N., \& LOGAN, G. D. (1986). On the autonomy of mental processes: A case study in arithmetic. Journal of Experimental Psychology: General, 115, 118-130.

\section{NOTES}

1. Personal information, 27 November, 1990.

2. Logan proposes a postlexical model in which attentional weights are assigned to the word. The magnitude of these weights is affected by the cue validity of the word as the (ink's) color predictor and is insensitive to the particular color-meaning relations. Thus, according to this model, control may be postlexical and yet not "reactive."

3. This analysis partially overlaps with the RT analyses reported in the previous section. Nevertheless, both analyses are reported to provide a comprehensive picture of the results.

4. We are aware that the contrasts defining the facilitation and inhibition components are not statistically independent; it therefore follows that the respective tests of interactions of comparisons are also not independent. Nevertheless, we decided to perform these tests due to their theoretical importance.

5. Following a suggestion of one of the reviewers, we performed separate tests of the interaction between facilitation and the proportion of color words for each type of neutral. In both cases; the interaction was far from significant $[F(2,33)=1.34 ; F(2,33)=1.85$, for word and nonword neutrals, respectively].

6. It has been suggested by one of the reviewers that some of the wond neutrals may have had a Stroop-like component. For example, it could be argued that lion is not a strict neutral in relation to yellow because lions are tannish-yellow.

7. The original response files of 2 subjects from the $50 \%$ color-words nonword-neutrals group were lost due to computer failure.
(Manuscript received March 14, 1991; revision accepted for publication April 15, 1992.) 